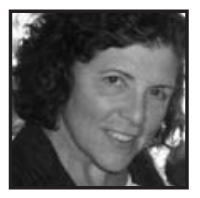

\title{
Commentary:
}

\section{The Politics of Curriculum Creativity}

\author{
Madeleine Grumet, University of North Carolina
}

\section{ABSTRACT (Press Here for Sound)}

As we encourage creativity in curriculum, we often forget that the whole agenda is made up. Creativity is the foundation of all knowledge and all curriculum. In this essay I argue that teachers do not need to be more creative, but do need to participate in the politics that will diminish our subordination. Because the creativity of the corporation and the testing companies has swamped the creativity of the classroom, the current economic crisis may provide opportunities for teachers to reassert the authority of our imaginations.

\section{Look, All Curriculum Is Made Up.}

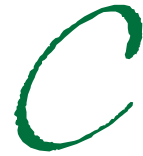

urriculum innovation does not suggest a radical or exceptional property or process of curriculum; it is its foundation. All of it has been made up. The so-called "basics" were selected from the disciplines of literacy and numeracy and are still contested. The bible, a founding text of Western schooling, is a collection of tales. Physical science is always under transformation. In August 2006, I was delighted to learn that at their annual meeting of the International Astronomical Union (IAU), astronomers from all over the world took a vote on the definition of a planet and consequently disqualified Pluto.

According to the new definition, a full-fledged planet is an object that orbits the sun and is large enough to have become round due to the force of its own gravity. In addition, a planet has to dominate the neighborhood around its orbit. 
Pluto has been demoted because it does not dominate its neighborhood. Charon, its large "moon," is only about half the size of Pluto, while all the true planets are far larger than their moons. (Inman, 2006)

This definition of a planet was supported by an obvious majority of IAU delegates, so votes were not counted, but a subsequent resolution identifying Pluto as a "dwarf planet" was contested, passing with 237 votes in favor, 157 against and 17 abstentions (International Astronomical Union, 2006).

There it was on the car radio. I know that these collective decisions about knowledge are being negotiated all the time, but rarely do you get to hear the vote as you are driving to the grocery store. And this decision, leaving us with eight instead of nine planets in our solar system, was both shocking and a little sad. What would we do with the mnemonic we had learned in elementary school: "My very elegant mother just served us nine pizzas." We had to console my five-year-old granddaughter, distraught that the smallest of the planets had been exiled from the family.

And so the designation of this body of rock and ice, two thirds the size of Earth's moon but 1,200 times farther away, travels from scientists scanning the universe at the Palomar Observatory, through the disciplinary deliberations of the IAU, to the news announcements of Pluto's demotion, to the charts and textbooks, and descriptions, that make my little granddaughter sad.

Creativity drives this knowledge and its dissemination all along the line. The creativity that is curriculum animates the inquiry, and the deliberations, and representations that we grasp as knowledge. It animates the communication of this knowledge in news announcements, journals, textbooks, and talk shows. It generates the codes and displays extended in the materials and syllabi of classrooms, from kindergarten to graduate school; and finally it generates the conversations between my granddaughter and her family and teachers. What should we say to her about Pluto? Will we speak of it in terms of epistemology, how what we know about the world is constructed? Will we talk about the Hubble Telescope and how it has provided information about the edge of our universe? Will we talk about her own family system, her younger siblings, and the ways that the littler and littlest ones have complicated her life?

At any given moment, in any classroom in any country, the curriculum that offers children important information about their world can be unraveled and questioned. All these choices that constitute knowledge and its presence in schools are 
generated by the social and material histories of the people who participated in them. Just to get on with the business of everyday life, however, we agree to a provisional version of the world, assuming that some of it is steady and stable, so that we can pay attention to pieces that are screaming for our attention and decisions.

As I write this piece, in the United States and in much of the world, the antic creativity of our banking and financial systems has been exposed, and these institutions which formerly enjoyed a spurious yet impressive reputation for reliability, are now understood to have been mystified about their own processes and dishonest in their representations of them. Although I recognize the suffering that job loss and loss of savings mean to populations around the world, I confess that I received the notice of this collapse a little bit like the news of Pluto, relishing the moment when knowledge is unmasked, revealing that under its apparent certainty and imposing demeanor is utter confusion.

Can we agree with President Obama that in crisis there is great opportunity (The Associated Press, 2009)? What kinds of creative opportunities do the current flux and sway of our world portend for curriculum? Do instabilities of finance, of national identities due to immigration and globalization, or of national security in the face of global terrorism, encourage legislators, administrators, parents and teachers to change curriculum?

Regrettably, I think that although schools rely on finance, and participate in national identities and national security, we imagine them to exist in a world apart that we think of as private, separate from the public institutions of money and war. This is the ancient division of public and private space, which feminist scholarship in the 1970s addressed, recognizing that the personal was political and the political was personal. This is also the legacy of romanticism that haunts our ideas about the past, about children and about ourselves, imagining children to be innocent, requiring us to shelter them from the contamination of society.

Feminist theory argued that these two domains, the personal and the political, are never independent of each other; instead, their relationship is dialectical, each containing customs, relations and practices that are possible because of those that exist in the other. In Bitter Milk: Women and Teaching (Grumet, 1988), I argued that schools provide opportunities to both men and women to compensate for the constraints they bear in their relationships to the next generation: men compensate for the inferential nature of paternity and the presence of mothers in our society as the primary parents by claiming the child through the codes of language, knowledge and 
public institutions; women compensate for the symbiotic relationship that they have with their progeny by greeting education and schooling as processes which may bestow independence on both them and their children.

The ironic result of these relations and their compensations is that women, who constitute the majority of teachers in our public schools, are recessive when it comes to the politics that shape schools, their financial support, their construction, organization, and curricula.

In the United States, the $A$ Nation at Risk (1983) report projected the blame for the failure of US automobile manufacturers to compete effectively with Toyota and Honda on to teachers and children. Our economy was failing, we were told, because teachers were not properly prepared and students were not learning and turning into productive workers. The next two decades saw curricula dominated by the pronouncements of corporate executives as school districts courted private finance and adopted the culture of industry for the languages of learning and teaching: standardization and accountability. Even as these industrialists are exposed as misguided, inadequately innovative and even worse, corrupt, schools continue to bear the weight of their curriculum innovations, visible in high-stakes testing, scripted instruction, and continuing attacks on the intelligence and preparation of teachers. The invasion of accreditation practices into the curricula and teaching of teacher education programs has only exacerbated this deadening of our work.

Teachers do not need to be more creative, more innovative than they are. Teachers need to engage in the politics that bring their authorship into the public debates, the elections, and the administration of schools. There are many ways to understand the exclusion of teachers from the public processes of curriculum. There is the history of the feminization of teaching which accompanied women's path from their kitchens to the classroom with an ideology of female nurture which portrayed us as gentle caregivers, but not as people capable of knowing the world and changing it. There is the history of sexism, relegating women to subordinate jobs, receiving less pay than our male counterparts. There is the failure of feminism to work simultaneously in universities and communities, abandoning the students and teachers in public schools for theories of identity that denied that they had any. There is the failure of collective bargaining that addressed blue collar wages and working conditions, but excluded teachers from negotiations about what goes on in the classroom. There is the failure of professionalization, which idealized the authority of knowledge, the so-called knowledge base, imposing university practices in the name of action research, and reinforcing the separation of teachers from children and families. 
Many years ago I wrote an essay that addressed these issues, "Where the Line Is Drawn" (in Bitter Milk, 1988). In it I celebrated the creativity of teachers but recognized the institutional practices and cultural histories that consistently obscure it. At that time I called for borrowing two spaces from the world of practicing artists: the studio and the gallery. The studio was the place for withdrawal, a space away from the children where teachers work, alone or with each other, to create curriculum. The gallery was the place where they presented that work, to each other, to other educators, and to parents.

But now it seems to me that teachers need to make another space, and it cannot be borrowed from the university, or the corporation, or the factory. This needs to be a place where the creative work of teachers is projected into public and political space. The Internet certainly provides a way for teachers to communicate with each other and join together to build this movement. The shared interests and intellectual energies of the millions of creative and passionate people who work with children in our schools could generate substantial political clout. But if teachers are to participate in the politics of curriculum innovation, we must recognize that creativity, like schooling, is not a private or romantic practice to be sheltered from the world. It will always be contested, as it should be.

In crisis there is great opportunity.

\section{References}

The Associated Press (2009). Obama: Crisis is time of 'great opportunity'. Retrieved March 7, 2009, from http://apnews. myway.com/article/20090307/D96P7GG0 o.html.

Grumet, M.R. (1988). Bitter milk: Women and teaching. Amherst: University of Massachusetts Press.

Inman, M. (2006). Pluto has been voted off the island. National Geographic News. Retrieved August 24, 2006, from http://news.nationalgeographic.com/new s/2006/08/060824-pluto-planet.html.
International Astronomical Union, General Assembly (2006). Result of the IAU Resolution, Prague. Retrieved August 24, 2006, from http://www.iau.org/public press/news/release/iau0603/.

The National Commission on Excellence in Education (2003). A nation at risk: The imperative for educational reform. Retrieved May 29, 2009, from http://www.ed.gov/pubs/NatAtRisk/index .html. 


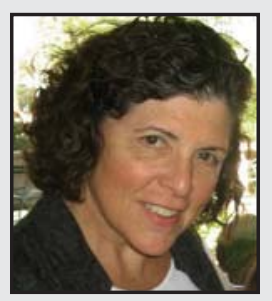

Madeleine Grumet is a professor of education and communication studies at the University of North Carolina, where she has served as dean of the School of Education. Prior to her appointment at Carolina, she served as dean of the School of Education at Brooklyn College, City University of New York. A curriculum theorist, specializing in arts and humanities curriculum, Professor Grumet has published many essays that interpret curriculum and teaching through the lenses of feminism, psychoanalysis and the arts. She is the author of Bitter Milk: Women and Teaching, a study of gender and the relationship of teaching and curriculum to experiences of reproduction. 